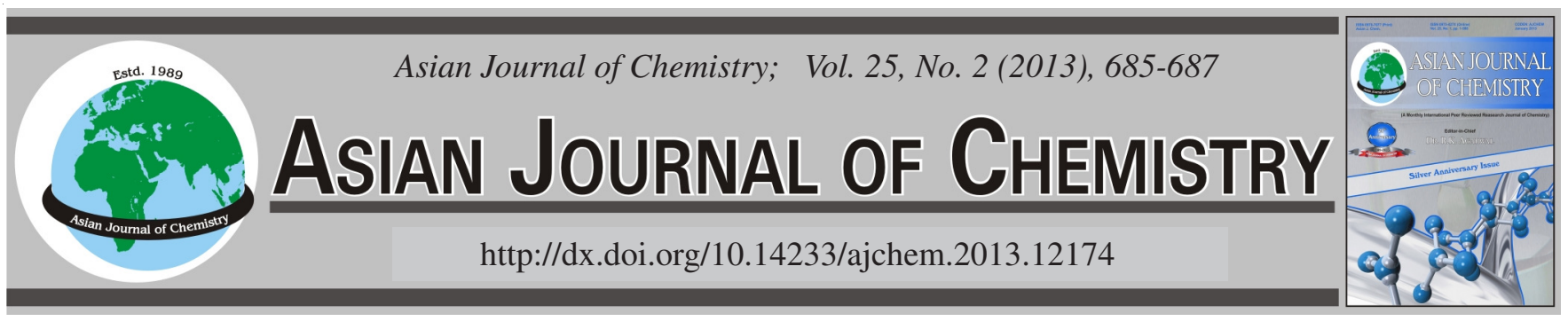

\title{
Synthesis and Structural Characterization of N-2,3-Dimethyl-5-oxo-1- phenyl-1H-pyrazol-4-yl-7-oxa-bicyclo[2,2,1]hept-5-ene-2,3-dicarboximide
}

\author{
Zu-PEI LIANG* and JiAn Li
}

Department of Chemistry and Chemical Engineering, Weifang University, Weifang 261061, P.R. China

*Corresponding author: Tel: +86 536 8877561; E-mail: lzpwfu@163.com

\begin{abstract}
Present compound N-2,3-dimethyl-5-oxo-1-phenyl-1 $H$-pyrazol-4-yl-exo-7-oxa-bicyclo[2,2,1]hept-5-ene-2,3-dicarboximide $\left(\mathrm{C}_{19} \mathrm{H}_{17} \mathrm{~N}_{3} \mathrm{O}_{4}\right.$, $\mathrm{Mr}=351.36)$ was synthesized and characterized by elemental analysis, ${ }^{1} \mathrm{H}$ NMR spectra, IR spectra and single crystal X-ray diffraction. The crystal belongs to orthorhombic, space group P212121, with $\mathrm{a}=6.4582(8), \mathrm{b}=15.8179(14), \mathrm{c}=16.2269(15) \AA, \beta=90^{\circ}, \mathrm{V}=$ $1657.7(3) \AA^{3}, Z=4, D_{c}=1.408 \mathrm{~g} / \mathrm{cm}^{3}, \lambda=0.71073 \AA, \mu\left(M_{0}\right)=0.101 \mathrm{~mm}^{-1}, F_{(000)}=736$. The final refinement gave $R=0.0326, w R\left(F^{2}\right)$ $=0.0723$ for 1,702 observed reflections with $\mathrm{I}>2 \sigma(\mathrm{I})$. The structure of the title compound comprises a racemic mixture of chiral molecules containing four stereogenic centres. X-Ray diffraction analysis reveals that the cyclohexane ring tends towards a boat conformation. The dihedral angle between the dihydropyrazole ring and the pyrrolidine ring and the aromatic ring is $82.0(1)$ and $57.3(1)^{\circ}$, respectively. The crystal structure is stabilized by $\mathrm{N}-\mathrm{H} \cdots \mathrm{O}, \mathrm{C}-\mathrm{H} \cdots \mathrm{O}, \mathrm{C}-\mathrm{H} \cdots \mathrm{N}$ and $\mathrm{N}-\mathrm{H} \cdots \mathrm{N}$ hydrogen bonds.
\end{abstract}

Key Words: N-2,3-Dimethyl-5-oxo-1-phenyl-1 $H$-pyrazol-4-yl-exo-7-oxa-bicyclo[2,2,1]hept-5-ene-2,3-dicarboximide, Synthesis, Structural characterization.

\section{INTRODUCTION}

The imide moiety is an integral structural part of various important bioactive molecules such as fumaramidmycin, granulatimide, isogranulatimide and rebeccamycin. These molecules are reported to exhibit antitumor, antiinflammatory and antimicrobial activities ${ }^{1-3}$. 7-Oxa-bicyclo[2,2,1]hept-5ene-2,3-dicarboxylic anhydride has been widely employed in clinical practice, as it is less toxic and much easier to be synthesized $^{4,5}$. Its derivatives are also pharmacologically active $^{6}$. Furthermore, exo-7-oxa-bicyclo[2,2,1] hept-5-ene-2,3dicarboximide and its $\mathrm{N}$-substituent compounds have recently become an intense research topic in heterocyclic chemistry because of their antitumor, antivirus, analgesic, sedative and fungicidal activities ${ }^{7}$. In this paper, the synthesis, molecular structure and antibacterial activities of the title compound are reported.

\section{EXPERIMENTAL}

Infrared absorption spectra were obtained from a Nicolet NEXUS 670 FT-IR spectrometer in KBr discs and were reported in $\mathrm{cm}^{-1}$ units. ${ }^{1} \mathrm{H}$ NMR spectra were determined on a Bruker DRX-400 NMR spectrometer with TMS as internal standard in DMSO- $d_{6}$. Carbon, nitrogen and hydrogen analyses were performed on an Elemental Analysensteme GmbH Vario EL analyzer. Furan, maleic anhydride and $o$-aminobenzoic acid were purchased from Weifang Runze (China). All other chemicals used in this work were of analytical grade.

Synthesis of the title compound: Exo-7-oxa-bicyclo[2,2,1]hept-5-ene-2,3-dicarboxylic anhydride was synthesised according to the literature ${ }^{8}$. A mixture of exo-7-oxa-bicyclo[2,2,1]hept-5-ene-2,3-dicarboxylic anhydride $(0.332 \mathrm{~g}, 2$ $\mathrm{mmol}$ ) and 4-amino-1,2-dihydro-2,3-dimethyl-1-phenylpyrazol5-one $(0.406 \mathrm{~g}, 2 \mathrm{mmol})$ in methanol $(5 \mathrm{~mL})$ was stirred for $1 \mathrm{~h}$ at room temperature and then refluxed for $1 \mathrm{~h}$. After cooling the precipitate was filtered and dried, the title compound was obtained. Yield: $82 \%$. The crude product of $20 \mathrm{mg}$ was dissolved in methanol of $10 \mathrm{~mL}$. The solution was filtered to remove impurities and then the filtrate was left for crystallization at room temperature. The single crystal suitable for $\mathrm{X}$-ray determination was obtained by evaporation from the methanol solution after $6 \mathrm{~d}$.

Anal. calcd. (\%) for $\mathrm{C}_{19} \mathrm{H}_{17} \mathrm{~N}_{3} \mathrm{O}_{4}: \mathrm{C}$ 64.95, $\mathrm{H} 4.84, \mathrm{~N} 11.96$. Found (\%): C 64.82, H 4.91, N 11.88. Selected IR (KBr, $v_{\max }$, $\left.\mathrm{cm}^{-1}\right)$ : 3057 (Ar-H), $2936(-\mathrm{C}-\mathrm{H}), 1770,1653(\mathrm{C}=\mathrm{O}), 1600$ $(\mathrm{C}=\mathrm{C}), 1562(\mathrm{C}=\mathrm{N}), 1194(\mathrm{C}-\mathrm{O}-\mathrm{C}), 719$ (=C-H). ${ }^{1} \mathrm{H}$ NMR (DMSO- $\left.d_{6}, \mathrm{ppm}\right) \delta: 7.23(\mathrm{~m}, 2 \mathrm{H}, \mathrm{ArH}), 6.78(\mathrm{~m}, 1 \mathrm{H}, \mathrm{ArH})$, $6.72(\mathrm{~d}, 2 \mathrm{H}, \mathrm{ArH}), 5.84\left(\mathrm{~d}, 2 \mathrm{H}, \mathrm{C}_{6} \mathrm{H}, \mathrm{C}_{7} \mathrm{H}\right), 4.67\left(\mathrm{~m}, 2 \mathrm{H}, \mathrm{C}_{5} \mathrm{H}\right.$, $\left.\mathrm{C}_{8} \mathrm{H}\right), 3.10\left(\mathrm{~d}, 2 \mathrm{H}, \mathrm{C}_{3} \mathrm{H}, \mathrm{C}_{4} \mathrm{H}\right), 2.51\left(\mathrm{~s}, 3 \mathrm{H}, \mathrm{C}_{14} \mathrm{H}\right), 1.74(\mathrm{~s}, 3 \mathrm{H}$, $\left.\mathrm{C}_{12} \mathrm{H}\right)$. 
Data collection and structure determination: The single crystal X-ray data of title compound was collected on a Bruker SMART diffractometer. The reflection data were measured at 298(2) K, using a graphite monochromator $\operatorname{MoK}_{\alpha}(\lambda=0.71073 \AA)$ radiation with an $\omega-2 \theta$ scan mode. The total reflections were 7614 with 1702 independent ones $\left(R_{\text {int }}=0.0352\right)$, of which 237 were observed with $\mathrm{I}>2 \sigma(\mathrm{I})$. Intensities were corrected for Lorentz and polarization effects and empirical absorption and all data were corrected using $\mathrm{SADABB}^{9}$ program.

The structure was solved by direct methods using SHELXS- $97^{10}$ program. The positions of the $\mathrm{H}$ atoms bonded to $\mathrm{C}$ atoms were calculated (C-H distance $0.96 \AA$ ) and refined using a riding model. The $\mathrm{H}$ atom displacement parameters were restricted tobe $1.2 \mathrm{U}_{\mathrm{eq}}$ or $1.5 \mathrm{U}_{\mathrm{eq}}$ (methyl C) of the parent atom. The contributions of these hydrogen atoms were included in the structurefactor calculations. The atomic scattering factors and anomalous dispersion corrections were taken from International Table for X-ray crystallography ${ }^{11}$. The final least-square cycle gave $\mathrm{R}=0.0326$ and $\omega \mathrm{R}=0.0723\left(\mathrm{w}=1 /\left[\sigma^{2}\left(\mathrm{Fo}^{2}\right)+\right.\right.$ $\left.(0.0378 \mathrm{P})^{2}+0.0856 \mathrm{P}\right]$, where $\left.\mathrm{P}=\left(\mathrm{Fo}^{2}+2 \mathrm{Fc}^{2}\right) / 3\right) . \mathrm{S}=1.175$, $(\Delta / \sigma)_{\max }=0.000,(\Delta \rho)_{\min }=-0.150$ and $(\Delta \rho)_{\max }=0.136 \mathrm{e} / \AA^{3}$. CIF file containing complete information on the studied structure was deposited with CCDC, deposition number 780542 and is freely available upon request from the following web site: www.ccdc.cam.ac.uk/data_request/cif

\section{RESULTS AND DISCUSSION}

Furan reacts in a Diels-Alder reaction with maleic anhydride in tetrahydrofuran at room temperature to give exo7-oxa-bicyclo[2,2,1]hept-5-ene-2,3-dicarboxylic anhydride, as shown in Scheme-I.<smiles>c1ccoc1</smiles><smiles>O=C1C=CC(=O)O1</smiles>

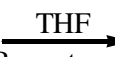
$\overrightarrow{\text { Room temp. }}$

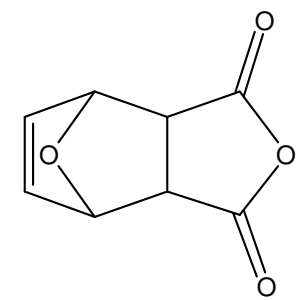

Scheme-I: Synthesis of exo-7-oxa-bicyclo[2,2,1]hept-5-ene-2,3dicarboxylic anhydride

The condensation reaction between exo-7-oxa-bicyclo[2,2,1]hept-5-ene-2,3-dicarboxylic anhydride and 4-amino1,2-dihydro-2,3-dimethyl-1-phenylpyrazol-5-one proceeded smoothly in methanol at room temperature for $1 \mathrm{~h}$ and refluxed temperature for $1 \mathrm{~h}$, respectively, leading to the title compound in high yield, as shown in Scheme-II. The elemental analysis, IR spectra and ${ }^{1} \mathrm{H}$ NMR data clearly indicated the condensation reaction of exo-7-oxa-bicyclo[2,2,1]hept-5-ene-2,3-dicarboxylic anhydride with 4-amino-1,2-dihydro-2,3-dimethyl-1-phenylpyrazol-5-one in a ratio of 1:1.

The molecular structures with the atom-numbering scheme are shown in Fig. 1 and the crystal packing of the compound is depicted in Fig. 2. The selected bond distances and angles are listed in Table- 1 .

The structure of the title compound, $\mathrm{C}_{19} \mathrm{H}_{17} \mathrm{~N}_{3} \mathrm{O}_{4}$, comprises a racemic mixture of chiral molecules containing four<smiles></smiles><smiles>Cc1ccc(-n2c(=O)c(N)c(C)n2C)cc1</smiles><smiles>Cc1c(N2C(=O)C3C4C=CC(O4)C3C2=O)c(=O)n(-c2ccccc2)n1C</smiles>

Scheme-II: Synthesis of the title compound

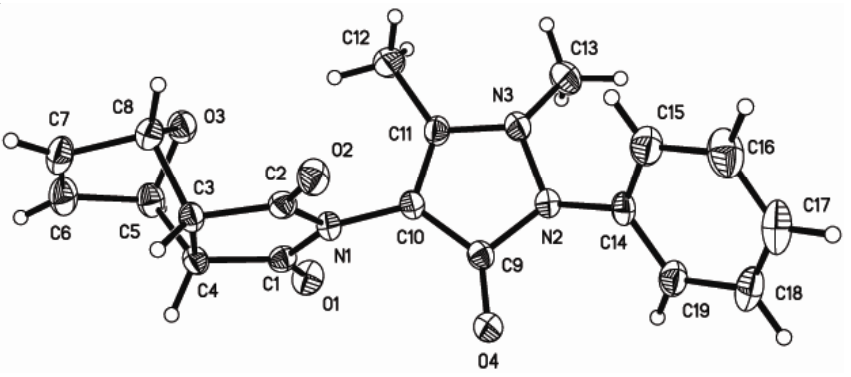

Fig. 1. Molecular structure of the title compound

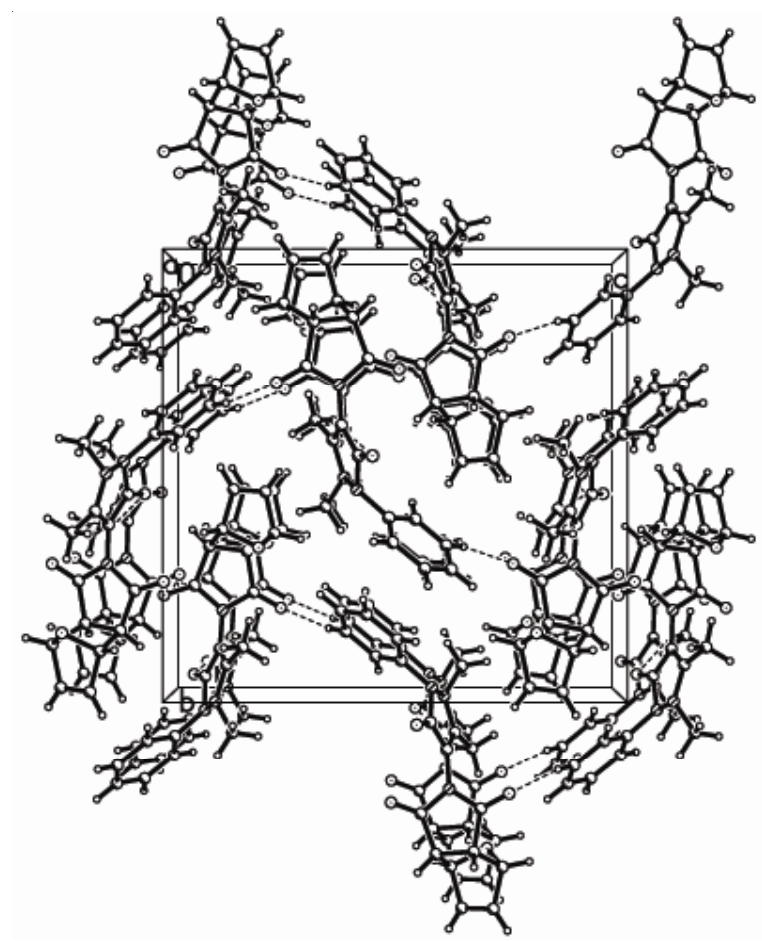

Fig. 2. Crystal packing of the title compound

stereogenic centres. As seen from Fig. 1, the cyclohexane ring tends towards a boat conformation and the tetrahydrofuran ring and the dihydrofuran ring adopt envelope conformations. The dihedral angle between the dihydropyrazole ring and the pyrrolidine ring and the aromatic ring is $82.0(1)$ and $57.3(1)^{\circ}$, respectively. As seen from Table-1, the bond lengths are expected $^{12}$. And they are comparable to those in the similar compounds ${ }^{13,14}$. In 7-oxabicyclo( $\left.2,2,1\right)$ hept-5-ene-2,3dicarboximide group, the $\mathrm{C}-\mathrm{C}$ bonds lengths [1.502(3)-1.563

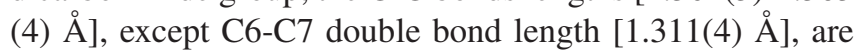




\begin{tabular}{cccc}
\hline \multicolumn{5}{c}{ TABLE-1 } \\
\multicolumn{4}{c}{ SELECTED BOND LENGTHS $(\AA)$ AND BOND ANGLES $\left(^{\circ}\right)$} \\
\hline \multicolumn{2}{c}{ Bond } & Length $(\AA)$ & \multicolumn{2}{c}{ Bond } & Angle $\left(^{\circ}\right)$ \\
\hline $\mathrm{N}(1)-\mathrm{C}(1)$ & $1.386(3)$ & $\mathrm{C}(1)-\mathrm{N}(1)-\mathrm{C}(2)$ & $113.0(2)$ \\
$\mathrm{N}(1)-\mathrm{C}(2)$ & $1.397(3)$ & $\mathrm{C}(1)-\mathrm{N}(1)-\mathrm{C}(10)$ & $125.4(2)$ \\
$\mathrm{N}(1)-\mathrm{C}(10)$ & $1.423(3)$ & $\mathrm{C}(2)-\mathrm{N}(1)-\mathrm{C}(10)$ & $121.3(2)$ \\
$\mathrm{N}(2)-\mathrm{N}(3)$ & $1.404(3)$ & $\mathrm{N}(3)-\mathrm{N}(2)-\mathrm{C}(9)$ & $108.4(2)$ \\
$\mathrm{N}(2)-\mathrm{C}(9)$ & $1.416(3)$ & $\mathrm{N}(3)-\mathrm{N}(2)-\mathrm{C}(14)$ & $117.0(2)$ \\
$\mathrm{N}(2)-\mathrm{C}(14)$ & $1.440(3)$ & $\mathrm{C}(9)-\mathrm{N}(2)-\mathrm{C}(14)$ & $119.2(2)$ \\
$\mathrm{N}(3)-\mathrm{C}(11)$ & $1.350(3)$ & $\mathrm{C}(11)-\mathrm{N}(3)-\mathrm{N}(2)$ & $108.1(2)$ \\
$\mathrm{N}(3)-\mathrm{C}(13)$ & $1.459(4)$ & $\mathrm{C}(11)-\mathrm{N}(3)-\mathrm{C}(13)$ & $124.6(2)$ \\
$\mathrm{O}(1)-\mathrm{C}(1)$ & $1.205(3)$ & $\mathrm{N}(2)-\mathrm{N}(3)-\mathrm{C}(13)$ & $117.2(2)$ \\
$\mathrm{O}(2)-\mathrm{C}(2)$ & $1.202(3)$ & $\mathrm{C}(5)-\mathrm{O}(3)-\mathrm{C}(8)$ & $95.7(2)$ \\
$\mathrm{O}(3)-\mathrm{C}(5)$ & $1.441(4)$ & $\mathrm{O}(1)-\mathrm{C}(1)-\mathrm{N}(1)$ & $124.4(2)$ \\
$\mathrm{O}(3)-\mathrm{C}(8)$ & $1.442(3)$ & $\mathrm{O}(2)-\mathrm{C}(2)-\mathrm{N}(1)$ & $123.8(2)$ \\
$\mathrm{O}(4)-\mathrm{C}(9)$ & $1.221(3)$ & $\mathrm{O}(4)-\mathrm{C}(9)-\mathrm{N}(2)$ & $123.3(3)$ \\
\hline
\end{tabular}

longer than the normal single bond length. The degree of lengthening of the $\mathrm{C}-\mathrm{C}$ bonds in the title compound is in good agreement with that of corresponding $\mathrm{C}-\mathrm{C}$ bonds in $\mathrm{N}$-methyl7-oxabicyclo(2,2,1)hept-5-ene-2,3-exo-dicarboximide ${ }^{13}$, exo-4-[(4-bromophenyl)amino]-10-oxa-4-azatricyclo$(5,2,1,02,6)$ dec-8-ene-3,5-dine ${ }^{14}$ and 4-(2-aminophenyl)-10oxa-4-azatricyclo $(5,2,1,02,6)$ dec-8-ene-3,5-dine ${ }^{15}$. The crystal structure is stabilized by and $\mathrm{N}-\mathrm{H} \cdots \mathrm{O}, \mathrm{C}-\mathrm{H} \cdots \mathrm{O}, \mathrm{C}-\mathrm{H} \cdots \mathrm{N}$ and $\mathrm{N}-\mathrm{H} \cdots \mathrm{N}$ intermolecular hydrogen bonds (Fig. 2 and Table-2).

\begin{tabular}{|c|c|c|c|c|}
\hline \multicolumn{5}{|c|}{$\begin{array}{c}\text { TABLE-2 } \\
\text { HYDROGEN BOND SCHEMES }\left(\AA,^{\circ}\right)\end{array}$} \\
\hline $\mathrm{D}-\mathrm{H} \cdots \mathrm{A}$ & D-H & $\mathrm{D} \cdots \mathrm{A}$ & D-A & D-H $\cdots A$ \\
\hline N2-H2A...N1 & 0.86 & 2.498 & 2.820 & 103 \\
\hline $\mathrm{N} 2-\mathrm{H} 2 \mathrm{~B} \ldots \mathrm{O} 2^{\mathrm{a}}$ & 0.86 & 2.275 & 3.131 & 174 \\
\hline $\mathrm{C} 3-\mathrm{H} 3 \ldots \mathrm{O} 1^{\mathrm{b}}$ & 0.98 & 2.480 & 3.232 & 133 \\
\hline $\mathrm{C} 8-\mathrm{H} 8 \ldots \mathrm{O} 2^{\mathrm{c}}$ & 0.93 & 2.594 & 3.369 & 141 \\
\hline $\mathrm{C} 14-\mathrm{H} 14 \ldots \mathrm{N} 2^{\mathrm{d}}$ & 0.98 & 2.610 & 3.484 & 149 \\
\hline
\end{tabular}

Symmetry codes: (a) 1/2-x, y, 1/2+z (b) -x, -y, -1/2+z (c) -x, 1-y, 1/2+z (d) $1 / 2-x, y,-1 / 2+z$.

\section{ACKNOWLEDGEMENTS}

This work was supported by Shandong Provincial Natural Science Foundation, China (No. ZR2010BM033).

\section{REFERENCES}

1. M.F. Brana, A. Gradillas, A. Gomez, N. Acero, F. Llinares, D. MunozMingarrro, C. Abradelo, F. Rey-Stolle, M. Yuste, J. Campos, M.A. Gallo and A. Espinosa, J. Med. Chem., 47, 2236 (2004).

2. S.M. Sondhi, R. Rani, P. Roy, S.K. Agrawal and A.K. Saxena, Bioorg. Med. Chem. Lett., 19, 1534 (2009).

3. A.A. Manesh, Asian J. Chem., 22, 5787 (2010).

4. L.P. Deng and Y.Z. Hu, J. Heterocycl. Chem., 44, 597 (2007).

5. L.P. Deng, F.M. Liu and H.Y. Wang, J. Heterocycl. Chem., 42, 13 (2005).

6. M.E. Hart, A.R. Chamberlin, C. Walkom, J.A. Sakoff and A. McCluskey, Bioorg. Med. Chem. Lett., 14, 1969 (2004).

7. G. Goksu, N. Ocal and D.E. Kaufmann, Molecules, 15, 1302 (2010).

8. H. Kwart and J. Burchuk, J. Am. Chem. Soc., 74, 3094 (1952).

9. G.M. Sheldrick, SADABS, Program for Empirical Absorption Correction of Area Detector Data, University of Gottingen, Germany (1996).

10. G.M. Sheldrick, SHELXTL V 5.1 Software Reference Manual, Bruker AXS, Inc., Madison, Wisconsin, USA (1997).

11. Siemens, SMART and SAINT, Area Detector Control and Integration Software. Siemens Analytical X-Ray Systems, Inc., Madison, Wisconsin, USA (1996).

12. F.H. Allen, O. Kennard, D.G. Watson, L. Brammer, A.G. Orpen and R. Taylor, J. Chem. Soc., Perkin Trans II, S1 (1987).

13. Y.W. Goh, B.R. Pool and J.M. White, J. Org. Chem., 73, 151 (2008).

14. N.R. Conley, R.J. Hung and C.G. Willson, J. Org. Chem., 70, 4553 (2005).

15. J. Li, Acta Cryst., E67, 588 (2011). 